\title{
Revista de la
}

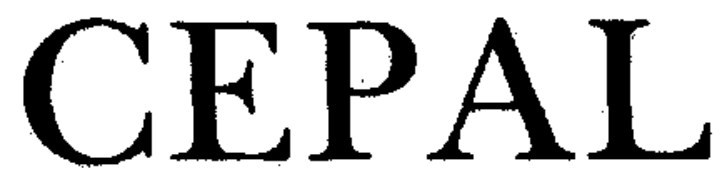

\author{
Secretario Ejecutivo \\ Norberto González \\ Secretario Ejecutivo Adjunto de \\ Desarrollo Económico y Social \\ Gert Rosenthal \\ Secretario Ejecutivo Adjunto de \\ Cooperación y Servicios de Apoyo \\ Robert T. Brown
}

\begin{abstract}
Director de la Revista
Raúl Prebisch

Secretario Técnico

Adolfo Gurrieri

Secretaria Adjunta

Rosa Nielsen
\end{abstract}

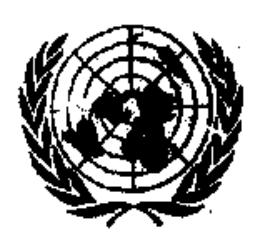

NACIONES UNIDAS

COMISION ECONOMICA PARA AMERICA LATINA Y EL CARIBE

SANTIAGO DE CHILE, ABRIL DE 1986 


\section{Revista de la \\ C E P A L}

Santiago de Chile

Número 28

\section{SUMARIO}

Exposición del Secretario Ejecutivo de la Comisión Económica para América Latina y el Caribe, Sr. Norberto González, al inaugurar la Reunión sobre el Crecimiento, el Ajuste y la Deuda en América Latina.

Centroamérica: bases de una política de reactivación y desarrollo. Subsede de la ckp,AL en México

Reflexiones sobre industrialización, articulación y crecimiento. División Conjunta ckpalle 'vano de Desarrollo Industrial

Inflación y políticas de estabilización. Daniel Heymann

Las empresas transnacionales en la Argentina, 1976-1983. Daniel Azpiazu, Eduardo Basualdo y Bemardo Kosacoff

Seguridad social y desarrollo en América Latina. Carmelo Mesa-Lago

Cambios de relevancia social en el transplante de teorías: los ejemplos de la teoría económica y la agronómica. Ivo Dubiel

La elaboración de inventarios y cuentas del patrimonio natural y cultural. Nicolo Gligo

Cooperativismo y participación popular: nuevas consideraciones respecto de un viejo tema. Roberto P. Guimarāes

Notas sobre el intercambio desde el punto de vista periférico. Raúl Prebisch

Publicaciones recientes de la CEPAL 
REVISTA DE LA GEPAL $\mathbf{N}^{\circ} 28$

\section{Notas sobre} el intercambio desde el punto de vista periférico

\section{Raúl Prebisch*}

La exigencia de generar divisas para cancelar los intereses de la deuda externa coloca otra vez sobre el tapete el tema de las relaciones comerciales entre centros y periferia, de la potencialidad que ellas encierran y de los obstáculos que las limitan.

El autor comienza por reiterar la persistencia de las causas estructurales que generan el desequilibrio comercial de los paises de la periferia - vinculadas directamente a la evolución de la elasticidad-ingreso de los precios internacionales de los productos manufacturados y primarios (excepto petróleo)-y las soluciones con que dichos paises han procurado enfrentarlo. Entre dichas soluciones examina en particular la sustitución de importaciones de los centros y la exportación de manufacturas hacia ellos.

La apertura de los mercados de los centros a las manufacturas de la periferia sería una medida de enorme potencialidad para esta última pero la variada gama de trabas y restricciones existentes no lo inclina hacia el optimismo. Por ello afirma que, en tales circunstancias, debe reverdecerse la antigua idea de la sustitución de importaciones en el amplio marco de la integración regional. No se trata de aplicar nuevamente políticas ideadas hace varios decenios; ellas pueden constítuir una solución al desequilibrio externo siempre que se las adecúe a la situación actual y se eviten los errores cometidos en el pasado. Ante un comercio mundial que se cierra, ellas representan un ingredien. te ineludible en cualquier estrategia razonada de desarrollo.

*Director de la Revista de la cepal.

\section{I \\ Innovación y diversificación de bienes y servicios y sus consecuencias sobre el intercambio}

La revolución tecnológica que viene ocurriendo en los centros, los acontecimientos monetarios de Estados Unidos, y los grandes desequilibrios en las relaciones econónicas internacionales plantean problemas muy serios para la periferia latinoamericana.

En artículos anteriores publicados en esta revista hemos sostenido una serie de tesis que son de gran atinencia con el tema del presente artículo.

Hemos tratado de demostrar que en el desarrollo histórico de los centros, como en los tiempos presentes, los grandes incrementos de pro. ductividad que el progreso técnico ha traído consigo no se han manifestado correlativamente en el descenso de los precios. La razón de esta diferencia de tanta importancia radica en la diversificación continua que las innovaciones tecnológicas traen en los bienes y servicios. Conforme aumenta el ingreso global, debido a la creciente productividad, la demanda se desplaza principalmente hacia nuevas formas de bienes y servicios antes que a los que ya venían produciéndose. Esta diversificación se da en los bienes manufacturados y no en los alimentos y otros bienes primarios donde el cambio y la diversificación son muy limitados.

Este fenómeno basta para explicar la tendencia al deterioro de los precios de los productos primarios en relación con los bienes manufacturados. Desde los primeros tiempos de la CEPAL hemos explicado que esta tendencia influía muy seriamente en las relaciones entre los centros y la periferia. Más aún, conforme el progreso técnico va penetrando en esta última y elevando el ingreso, se manifiesta también el mismo fenómeno de diversificación incesante de la demanda, acentuada generalmente por las grandes fallas en la distribución del ingreso.

La periferia se encuentra así expuesta a un fenómeno de desequilibrio exterior a medida que avanza el proceso de desarrollo, que tiene que rectificarse para que éste pueda cumplirse. 
En efecto, la diversificación de la demanda impulsa a las importaciones a crecer con ritmo generalmente muy elevado, mientras las exportaciones de productos primarios, salvo las de petróleo, tienden a crecer con un ritmo relativamente lento. Este fenómeno viene dándose de tiempo atrás, sometido siempre a las consecuencias de los ciclos de los centros.

Los economistas de los centros en general atacaron primero la industrialización de la periferia, que se inició durante la gran depresión mundial, y después han abominado de la sustitución de importaciones, recomendando en su lugar a la periferia exportar manufacturas para hacer frente a aquella tendencia al desequilibrio.

Hay países en la periferia latinoamericana que tomaron seriamente este consejo y emprendieron un gran esfuerzo de exportación. Sucede sin embargo que cuando estas exportaciones empezaron a competir con la producción de los centros, éstos no tardaron en someterlas a serias restricciones. Explicanse estas restricciones por el desempleo que el debilitamiento dinámico de los centros ha traido consigo en tiempos recientes. Sin embargo, en los largos años de prosperidad que terminan en la primera mitad de los años setenta, donde en algunos países no solamente no hubo desocupación sino que se admitieron trabajadores extranjeros, no se dio un esfuerzo manifiesto para desbaratar el tratamiento arancelario adverso que sufren no solamente los productos primarios sino también los bienes manufacturados provenientes de la periferia.

En UNCTAD se desenvolvieron intensos esfuerzos para cambiar este estado de cosas sin resultados positivos. Esto me hace pensar que hay factores muy serios que se oponen a una política de liberalización de las importaciones provenientes de la periferia. En efecto, en esos años de prosperidad en las grandes rondas de negociaciones del GATT (Kennedy y Tokyo) las tarifas aduaneras se redujeron a un nivel muy bajo, pero esto concierne principalmente al intercambio de los centros, que en gran parte está dado precisamente en aquellos bienes en donde es muy intenso el proceso de diversificación debido a las continuas innovaciones tecnológicas, $y$ por el impulso de las companías transnacionales, las que al realizar estas innovaciones han intervenido activamente en dicho intercambio, el que alcanzó cifras extraordinariamente altas. No es extraño entonces que la periferia, que habia empezado a exportar bienes tecnológicamente poco avanzados y de muy escasa diversificación, haya quedado notoriamente a la zaga en esta expansión del intercambio de manufacturas.

Ya he señalado que existen factores que explican la adversa reacción de los centros a la importación de manufacturas provenientes de la periferia. Creo que para comprender este hecho es indispensable recordar el papel dinámico del excedente económico de las empresas que he procurado explicar en artículos anteriores.' En el excedente se manifiesta principalmente el fruto de la creciente productividad del sistema que no se transfiere a la fuerza de trabajo. Esto tiene profunda significación dinámica puesto que del excedente sale una parte considerable de la acumulación de capital de las empresas. Así, conforme evoluciona la demanda hacia una creciente diversificación, se desplaza también la inversión de capital para producir los bienes que se diversifican. La competencia entre las empresas se dirige a ganar mercados en el proceso de diversificación más que al descenso de los precios, salvo en aquellos bienes superados por otros provenientes de aquellas incesantes innovaciones.

Hay aquí un hecho que tiene que subrayarse: ese desplazamiento de las inversiones se realiza gracias al crecimiento del excedente y ese crecimiento ocurre precisamente porque no bajan en general los precios de las manufacturas gracias a la diversificación. Si no hubiera diversificación, gracias a incesantes innovaciones, el consumo tendería a saturarse.

Este es un fenómeno característico del desarrollo capitalista. Sucede sin embargo que cuando las importaciones de la periferia adquieren capacidad competitiva, al combinarse el progreso técnico con salarios relativamente bajos, esta competencia se realiza mediante la baja de precios y afecta adversamente el crecimiento del excedente y la aptitud de las industrias afectadas por la competencia para desplazarse mediante inversiones en el proceso de diversificación o aumento de su productividad. Explícase así la resistencia de empresas y trabajadores a las im-

\footnotetext{
'Véase en especial "La periferia latinoamericana en la crisis del capitalismo", Revista de la CEPAL, $\mathrm{N}^{\circ} 26$, agosto de 1985.
} 
portaciones provenientes de la periferia. Es claro que a este fenómeno se agrega actualmente el desempleo que, como hemos dicho, proviene del entorpecimiento dinámico de las economías de los centros.

Los centros han venido defendiéndose con toda suerte de medidas restrictivas que se toman unilateralmente al margen de los compromisos del GATT. Estamos pues presenciando un fenómeno que no se había dado antes en el desarrollo capitalista y que, a mi juicio, es de carácter estructural y que si bien hasta ahora ha alcanzado moderadas proporciones, podría llegar a ser de gran importancia, conforme se vayan agregando otros a los pocos países periféricos que han aprendido a exportar manufacturas. Frente a ello es el caso preguntarse si, aun cuando se restableciera la dinámica de los centros, éstos estarian dispuestos a liberalizar las importaciones provenientes de la periferia.

Sin embargo, siguen proclamando la necesidad de liberalizar el intercambio. No ha disminuido su adhesión a los principios neoclásicos que han vuelto a adquirir gran relevancia tanto internamente como en las relaciones internacionales. Se mantiene la pureza de la doctrina acaso porque ello contribuye a aliviar la conciencia de quienes en la práctica la están violando. (A Dios rogando y con el mazo dando).

Todo ello es muy lamentable porque tales restricciones privan a unos y otros de las ventajas del intercambio de bienes tecnológicamente avanzados de los centros con bienes menos avanzados de la periferia, con indiscutibles ventajas recíprocas. Pero ¿cuál es la solución? Por supuesto que la solución no está en mantener o acentuar esas restricciones ni en eliminarlas completamente sino en regular el intercambio en forma tal que la periferia pueda participar en el incremento del consumo de los centros sin provocar trastornos. En efecto, si desea atacar su tendencia al desequilibrio externo, la periferia tendría que bajar sus precios en las industrias respectivas, lo cual disminuiría su capacidad de acumulación; también las empresas pertinentes de los centros sufririan los trastornos a que antes me he referido. Hay pues que buscar fórmulas que aseguren las ventajas del intercambio recíproco.

\section{II}

\section{Importancia de la protección}

Pero los centros se opusieron, primero a la industrialización periférica y después a la sustitución de importaciones, mediante la protección aduanera. En la CEPAL, desde los primeros tiempos, sostuvimos que la protección era indispensable a fin de hacer frente a la superioridad técnica y económica de aquéllos. Desgraciadamente, la protección ha sido por lo general muy exagerada, si no abusiva, y se mantuvo por mucho tiem. po sin estimular a las industrias a que redujeran sus costos de producción, punto sobre el cual volveremos más adelante. Los adeptos a las doc. trinas neoclásicas impugnan la protección. Terminan admitiendo la industrialización pero siempre que ella sea un fenómeno espontáneo y no el resultado de la intervención del Estado en el juego de las fuerzas del mercado. Lo más que llegaron a admitir fue el recurrir a la devaluación monetaria a fin de lograr efectos similares a los de la protección. Pero acaso no comprendieron cabalmente que la devaluación traería consigo el descenso de los precios internacionales de los bienes primarios que eran competitivos. Recuerdo que medidas de esta naturaleza fueron recomendadas a nuestros países por técnicos del Fondo Monetario Internacional; cuando se les hacía notar este efecto adverso sobre los precios dijeron que podía subsanarse estableciendo impuestos a las exportaciones, con lo cual contradecían su propia doctrina liberal, puesto que un impuesto a las exportaciones significa una intervención del Estado en las fuerzas del mercado similar a la del impuesto a las importaciones. Si recuerdo esto es para señalar que nuestros fenómenos no siempre han sido objeto de clara comprensión en el pensamiento de los centros.

Más de una vez me ha preocupado en tiempos recientes por qué en lugar de las restricciones 
que los centros aplican a las importaciones periféricas no se recomienda la devaluación a fin de poner a las industrias de los centros afectadas por la competencia en condiciones de resistirla, bajando en esta forma los, salarios reales. Baste mencionar este solo hecho para darse cuenta de la índole de estas recomendaciones puesto que aun en los casos que esta medida hubiera sido social y políticamente viable, el descenso de salarios habría llevado también al deterioro de los precios de todas las industrias que son competitivas, esto es, al deterioro de la relación de precios del intercambio de los centros.

En verdad, las teorías económicas no siempre prevalecen por su rigor científico sino por los intereses que favorecen, $y$ esta consideración me lleva o otro aspecto del tema que estamos analizando. En otro lugar me referi a la oposición de los economistas de los centros a la industrialización periférica. Desde sus primeros tiempos la CEPAL sostuvo que la industrialización era una exigencia insoslayable del desarrollo. Esta tesis nuestra fue comentada a comienzos del decenio de $\mathbf{1 9 5 0}$ por el Profesor Jacob Viner, una de las autoridades más conspicuas en materia de comercio internacional. Como nos ha sucedido con frecuencia, el Profesor Viner había leído versiones indirectas de nuestras ideas y así, para impugnar la tesis de la industrialización, nos atribuyó el concepto según el cual la agricultura empobrecía a los pueblos en tanto que la industria elevaba su bienestar. Cuando pocas semanas después fui invitado para ocupar la misma cátedra en la Universidad de Brasil expresé: ¿cómo podría yo sostener esa idea tan peregrina si mi país, la Argentina, alcanzó en el comienzo de este siglo una de las cifras más elevadas del mundo de ingreso por habitante? El Profesor Viner sostenía que, en lugar de industrializarse, la periferia tenía que introducir el progreso técnico en la agricultura, tesis desde luego irrefutable, pero que negaba la experiencia de todos los países, independientemente de su sistema económico y social. En efecto, a medida que el progreso técnico elevaba la productividad de la agricultura, disminuía su capacidad de absorción de empleo y habia que buscar otras formas para absorber la fuerza de trabajo redundante. De ahí uno de los papeles dinámicos fundamentales de la industrialización. De lo contrario, la fuerza de trabajo redundante tendria un serio efecto depresivo sobre los salarios y, en consecuencia, sobre los precios internacionales de la producción agropecuaria.

Yo creo que este último argumento es decisivo, pero al conversar acerca de ello en los centros me convencí de que esto, lejos de preocupar a algunos de sus economistas, contribuia a reforzar la tesis de Viner puesto que convenía a los centros el descenso de los precios de los productos primarios que adquirían en la periferia.

Corresponde ahora plantearse esta otra pregunta: ¿por qué los centros reciben con beneplácito el descenso de los precios de estos productos primarios en tanto que se empeñan en resistir el descenso de los precios de las manufacturas que importan desde la periferia? La respuesta es muy simple. El descenso de los precios de los productos primarios agranda el excedente económico de las empresas que los adquieren, en tanto que el descenso de los precios industriales debilita su excedente y en consecuencia su capacidad de acumulación, como dije anteriormente.

Ahora permitaseme volver sobre la protección en la periferia. Decía que es indispensable introducir el progreso técnico en la agricultura y en general en la producción primaria y que sin la industrialización se corría el riesgo del deterioro de la relación de precios. Pero es claro que la industrialización cumple con relativa lentitud su función absorbedora de fuerza de trabajo y lo que se necesita es tratar de frenar el deterioro. Ello se consigue precisamente por la protección, puesto que al intensificar la actividad industrializadora contribuye a desplazar el capital y fuerza de trabajo de la producción primaria hacia la industrial. Pero esto no significa que no se hayan cometido gravisimos errores en esta materia en América Latina, exagerando la protección en forma tal que ello terminaba afectando adversamente la producción primaria, argumentoque se ha usado muchas veces contra la industrialización en vez de referirse a una mala política para realizarla. 


\section{III}

\section{El deterioro de los términos del intercambio}

Quisiera entrar ahora a las consideraciones sobre la tendencia al deterioro que tanto y con tanta razón nos preocupó en los primeros escritos de la CEPAL. Los productos agrícolas y en general los primarios no admiten gran diversificación. Es cierto que la fuerza de trabajo y el capital dedicados a producir un bien cuyo precio tiende a descender podrían dedicarse a producir otros bienes primarios, pero éstos, a su vez, están sujetos al riesgo de un fenómeno similar de saturación. En cambio en la producción industrial, el desplazamiento de la demanda y la correspondiente inversión del excedente y de los fondos de amortización para responder a este desplazamiento atenúan o impiden este fenómeno de saturación. Tal es la situación de inferioridad que desde este punto de vista corresponde a la agricultura, sobre todo cuando el progreso técnico tiende a aumentar con celeridad la productividad sin que la demanda se acreciente en cuantía necesaria para evitar el descenso de los precios.

Tal es el fenómeno notorio en los centros industriales, donde el considerable progreso técnico en la agricultura en los últimos decenios ha traído un incremento extraordinario de la producción; así, por ejemplo, en los Estados Unidos se ha limitado en distintas formas la producción de grano, a fin de evitar o moderar la caída de los precios internacionales, y esto ocurre aun en tiempos en que prevalecen las teorías neoclásicas. En los paises de la Comunidad Económica Europea ha ocurrido un fenómeno similar y es bien sabido que la tendencia al deterioro se ha atacado mediante algunos subsidios a los precios o prohibición de las importaciones. No niego los fenómenos de fondo que conducen a esta politica, sobre todo después de la experiencia de dos guerras mundiales que aconsejan no desbaratar la agricultura. También está de por medio el excedente agrícola según las consideraciones que he formulado en otro lugar. Pero de ello a producir grandes sobrantes y lanzarlos a cualquier precio al mercado internacional hay una enorme distancia. Sin embargo, ello se ha hecho y se sigue haciendo gracias a los subsidios internos, como en los Estados Unidos con la famosa ley 280 que de hecho significa un subsidio a la venta de granos en el exterior, especialmente en el mundo en desarrollo.

Todo esto se hizo al margen de los principios del GatT. Y no sólo eso, sino que se ha combatido a la periferia, y especialmente a la cEPAL, cuando exponíamos la tendencia al deterioro de la relación de precios en el intercambio de productos primarios. También en este caso se presentó erróneamente nuestra tesis sin explicar en qué términos la habíamos formulado. Más aún, se nos atribuyó acusar a los centros de explotar deliberadamente a la periferia mediante el deterioro de la relación de precios. Es cierto que se han practicado y se siguen practicando diversas formas de succión de ingresos periféricos pero la CEPAL no vinculó el deterioro con tesis alguna de explotación, que por lo general obedecen a consideraciones de índole política.

Después de estos esclarecimientos teóricos llegamos a un problema de la mayor importancia, a saber, ¿cómo atacar la tendencia hacia el desequilibrio estructural en nuestras relaciones con los centros? Ya se ha dicho anteriormente que se debía estimular las exportaciones a los centros y sustituir importaciones. Ahora bien, las exportaciones dependen fundamentalmente de la capacidad receptiva de los centros en función de su tasa de desarrollo y de su disposición a encontrar fórmulas que permitan a la periferia participar en su incremento de consumo o eventualmente en su mismo consumo. En la medida en que no nos sea posible hacerlo, sólo queda la sustitución de importaciones. La sustitución no es pues una preferencia doctrinaria sino que responde a condiciones objetivas de la realidad en nuestras relaciones con los centros.

Ahora bien, el problema es bastante complejo puesto que hay que determinar qué bienes convendría sustituir. Podríamos plantear este problema en los siguientes términos: hay bienes en que la sustitución ya ha ocurrido y hemos adquirido capacidad competitiva. Esto en un ex- 
tremo; en el otro extremo hay otros bienes que corresponden a los continuos avances de la tecnología de los centros tanto en materia de bienes de capital como de insumos y bienes de consumo. No cabría por el momento pensar en la sustitución de esos bienes por razones obvias. Entre esos dos extremos hay una amplia gama de bienes en que hemos adquirido o podriamos adquirir fácilmente capacidad tecnológica, y es en ellos donde habrá que examinar las posibilidades de sustitución con criterio selectivo, eligiendo aquellos bie- nes más susceptibles de producir en condiciones económicas en lugar de aquellos otros en que no nos es posible, por el tipo de nuestro desarrollo, enfrentar su producción.

Es bien sabido que la sustitución de importaciones en los mercados nacionales relativamente pequeños de nuestros países, no sólo por su población sino también por sus ingresos relativamente bajos, tropieza con muy altos costos. De ahí la necesidad de ampliar los mercados nacionales mediante la integración regional.

\section{IV}

\section{Necesidad de nuevas fórmulas de integración}

Hay que reconocer, sin embargo, que el esfuerzo que se ha realizado en más de dos decenios ha dado escasísimos resultados. Conviene pues examinar seriamente las razones por las cuales no hemos avanzado como se hubiera creído posible hacerlo en los primeros tiempos. Un examen retrospectivo me lleva a la conclusión siguiente: en la CEPAL nos dejamos seducir por la idea de un mercado común latinoamericano, que se fue abriendo paso y llego a concretarse en los arreglos conocidos. No digo que haya que abandonar esta idea, sino cambiar la forma y el tiempo de realizarla. Lo fundamental ha sido y sigue siendo la tendencia al desequilibrio con los centros que tiene que llevarnos necesariamente a sustituir las importaciones provenientes de ellos. A mi juicio, es alli donde hay que concentrar los esfuerzos, dejando para una etapa posterior otras medidas de liberalización del intercambio. Así por ejemplo las preferencias que podrían otorgarse recíprocamente nuestros paises para realizar importaciones de bienes de consumo no nos van a resolver ese problema fundamental que mencionamos. Pero no es eso solamente; yo creo que la sustitución de importaciones dentro de un régimen preferencial tropieza con grandes obstáculos. En efecto, los países más avanzados industrialmente están en condiciones de exportar bienes de capital o bienes intermedios a los paises menos avanzados o medianamente avanzados sin que éstos puedan participar en la misma medida en este género de intercambio. Sin embargo, tiende a recaer sobre ellos el costo de estas operaciones puesto que significa hacerles pagar precios más altos que los del mercado internacional por los bienes de capital e insumos que importan de los más avanzados. Por eso y por otras consideraciones, me inclino más bien a que los países avanzados otorguen a sus exportaciones subsidios equivalentes a lo que significa su protección aduanera. Por supuesto que el régimen de subsidios tendría que establecerse de común acuerdo con un nuevo convenio, pero no bastaría por sí mismo para asegurar un intercambio relativamente equilibrado. Los países menos avanzados o medianamente avanzados siempre estarían en inferioridad de condiciones si no se tomaran medidas especiales para superarla; una de ellas sería la de que los países más beneficiados por este intercambio compartieran con los menos las inversiones necesarias para llegar a un equilibrio satisfactorio de carácter no bilateral sino multilateral entre todos los países participantes.

Ello tendría otra ventaja muy significativa: los arreglos que, dentro del régimen existente, realizaran dos paises para especializar su producción con fines de intercambio recíproco no podrían quedar abiertos a la intervención de otros países latinoamericanos sin vulnerar las condiciones en que tales arreglos se basan. Por el contrario, un régimen de subsidios permitiría la incorporación de terceros países dispuestos a responder a los principios generales en que se basara un convenio de esta naturaleza. 
Como es sabido, hay resistencia de los centros al régimen de subsidios, no obstante las diversas formas encubiertas de otorgarlos respecto de sus propias exportaciones. Pero no podrian objetar a arreglos de esta naturaleza en países de la periferia. Esta idea no es en verdad nueva. Recuerdo que, a comienzos del decenio de 1960 , en uno de nuestros informes dijimos que la industrialización latinoamericana se había desenvuelto en forma asimétrica puesto que se estimulaba la sustitución sin dar un estímulo equivalente a la exportación de manufacturas.

Creo que hay que considerar seriamente la conveniencia de dar un nuevo giro a la política de integración como acabo de decirlo. No estoy haciendo una propuesta concreta sino sencillamente enunciando la conveniencia de alejarse de lo que pensábamos hace más de un cuarto de siglo cuando la industrialización apenas había alcanzado moderadas dimensiones y sin que tuviéramos como ahora la ventaja de haber recogido experiencias. Quiero señalar también que los países medianamente avanzados y los menos avanzados podrían participar en estas nuevas formas de intercambio con exportaciones de bienes de consumo, las que podrían realizarse con arreglos o fórmulas reguladoras similares a las que he mencionado en el caso de nuestras exportaciones a los centros.

\section{V \\ Posible cooperación de los centros}

En el desenvolvimiento de industrias que responden a la exigencia de más amplios mercados la cooperación de los centros podría ser de gran importancia. Pero ¿qué interés tendrían en apoyar nuestros esfuerzos de sustitución de las importaciones provenientes de ellos mismos? La respuesta es muy simple. La sustitución nos permitiría importar bienes de avanzada tecnologia en vez de importar bienes menos avanzados tecnológicamente, lo cual es de evidente ventaja para las dos partes. Además, se abriría en esta forma un amplio campo de transferencia de tecnología a los países periféricos con claras ventajas para los centros que, además de avanzar en la diversificación mediante nuevas tecnologías, tendrian la ventaja de negociar con los países periféricos la transferencia de tecnologías que están siendo ya superadas por otras más avanzadas, ampliando en esta forma su campo de acción. Estas dos consideraciones acaso podrían llevar al Banco Mundial, así como al BID, a participar activamente en la financiación de las inversiones necesarias. Ello permitiría fortalecer la posición de las empresas latinoamericanas, sean privadas o públicas, en diferentes formas de cooperación con las de los centros.

Las consideraciones que hemos formulado anteriormente nos permiten comprender el es- fuerzo que están haciendo los paises más importantes por abrir paso a sus exportaciones de avanzada tecnología. El caso más interesante que se ha planteado recientemente atañe a la ley de comercio y aranceles, que acaba de ser dictada en Estados Unidos. La electrónica, en sus distintas ramas, y la biotecnología constituyen la expresión más conspicua de la revolución tecnológica que se está operando en estos momentos en el mundo desarrollado y es natural que los Estados Unidos, asi como otros países, se preocupen de ampliar sus mercados, sujetos por cierto a una intensa competencia. Parece ser que para lograr este propósito, los Estados Unidos se proponen dar incentivos que promuevan el mercado de sus productos en los países periféricos, e incluso se habla de concesiones comerciales que se harían en forma bilateral. De ser ello así, nos alejariamos de una de las conquistas más importantes que se ha logrado en la economía internacional, o sea, el multilateralismo. Me inclino a creer, sin embargo, que ello significaría más bien la negociación bilateral para conseguir ventajas, más que un cambio fundamental. Pero aparte de ello cabe preguntarse ¿qué es lo que podrían hacer los Estados Unidos para que la demanda de importaciones de bienes avanzados realizada por los paises periféricos pueda ir acompañada de acre- 
centamiento de nuestras exportaciones a los Estados Unidos? Yo he expresado anteriormente mis dudas acerca de esta posibilidad y admitiré sin embargo estar equivocado si se nos presentan posibilidades concretas de aumento del inter. cambio en términos adecuados. Pero aun sin desdeñar estas posibilidades, en caso de plantearse, quiero insistir - como he hecho anteriormenteacerca de las ventajas que tendría para los centros la sustitución de importaciones periféricas. Sería la forma más efectiva para abrir mercados a los bienes de avanzada tecnologia.

El empeño de los Estados Unidos no se limita sin embargo a dichos bienes sino también a los servicios. Hay una amplia gama de estos servicios que está experimentando las consecuencias de la revolución tecnológica pero ¿qué ventajas tendría para nuestros países admitir, por ejemplo, una plena liberalización de la banca de los Estados Unidos en competencia con la de nuestros países? Yo creo que en muchos casos ya se ha ido demasiado lejos en esta materia y que no habría ventajas en seguir extendiendo las facilidades que se han dado en el pasado. Es cierto que los avances tecnológicos de las operaciones bancarias representan indudables ventajas, pero no lo es menos que podrían tomarse medidas que promuevan los avances tecnológicos en la banca nacional. Hay diversas consideraciones en favor de medidas de esta naturaleza, porque las menores remesas de beneficios que se harian en esta forma, gracias a la sustitución nacional de estos servicios, podrían dedicarse con mayores ventajas a la importación de bienes de tecnología avanzada, sea de capital, de insumos o bienes de consumo que la diversificación incesante presenta a nuestros paises.

\section{VI}

\section{El interés de los centros y el interés de la periferia}

Considero que frente a estos desafíos se impone un examen cuidadoso de necesidades y posibilidades sin dejarse seducir por las ideas que provienen de los centros. Hay que examinarlas cuidadosamente, hay que hacerlas pasar por el severo tamiz de nuestras coveniencias sin olvidar un concepto fundamental: los centros sólo se han interesado por el desarrollo periférico en la medida en que ello respondía a sus intereses económicos, políticos o estratégicos. No podríamos reprochar que país alguno promueva sus propios intereses, pero esto no significa que las ideas y sugerencias provenientes de afuera tengan que aceptarse como tales sin discernir el propio interés de nuestros países. El reproche tendría que recaer sobre los que adoptan ligeramente esas ideas y sugerencias sin ese previo examen de conveniencias.

Estoy persuadido por lo demás de que se ha llegado a una etapa en las relaciones con los centros en que es posible encontrar amplias zonas de convergencia de intereses $y$, por ello, me he per- mitido hacer las consideraciones que expuse anteriormente. Hay amplias zonas de convergencia de intercambio y de inversiones extranjeras. El examen que hay que hacer ha de responder a nuestras propias experiencias. Ya recordé anteriormente la oposición a la industrialización primero, a la sustitución de importaciones después. Se nos da el consejo de exportar manufacturas en vez de sustituir y cuando aprendemos a hacerlo se nos ponen obstáculos. La sustitución de importaciones se tomó durante largo tiempo como un engendro maléfico de la cepal. Pero los tiempos están cambiando estas concepciones. El año pasado la doctora Annie Kruger, importante funcionaria del Banco Mundial, al pasar por Santiago de Chile, criticó duramente la sustitución de importaciones; sin embargo, en el último discurso del señor Clausen, Presidente del Banco Mundial, a la Junta de Gobernadores, habló de la necesidad de exportar manufacturas y también de la sustitución de importaciones, lo que hace esperar que en un nuevo avance intelectual el 
Banco reconozca también la necesidad de promover el intercambio recíproco en la periferia latinoamericana. Más aún, el Profesor Bela Balassa, consultor del Banco Mundial, que había criticado sistemáticamente la posición de la CEPAL en esta materia, ahora habla también de sustitución de importaciones y de la exportación de manufacturas. El señor de Larossiére, Director General del Fondo Monetario Internacional, también acepta estas ideas.

Todo esto atañe igualmente a la condicionalidad. Se nos dice ahora que el Banco Mundial establecerá una condicionalidad como el FMI en los préstamos destinados a cambios estructurales. Yo creo que operaciones de préstamos de gran envergadura tienen que ir acompañadas de condicionalidad, pero ¿qué condicionalidad? Esa condicionalidad, determinada según el propio concepto de desarrollo de los centros jresponde a las exigencias del desarrollo periférico? Que yo sepa, nunca se ha discutido con economistas latinoamericanos el concepto de condícionalidad, sino que se ha dictado desde el Norte. Una eficaz política de cooperación exige también aquí un cambio importante. Hay que trabajar en ese sentido porque naturalmente las ideas que responden exclusivamente a los intereses de los centros están muy arraigadas. Acaso el ejemplo más im- presionante lo ha dado The Economist de Londres cuando en el número del 30 de noviembre de 1985, manifestó en su propia carátula que los países pobres habian hecho una donación de 65000 millones de dólares a los países desarrollados por efecto del deterioro de los precios de los productos primarios. Esto, según The Economist, permitirá atenuar en los centros las alzas de precios que podría provocar una política expansiva, lo que parece muy aconsejable. Sin embargo, no se hace otra referencia a la periferia como decir, por ejemplo, que una posible baja de las tasas de interés sería también ventajoso para ella. No hay ninguna referencia por cierto a la gravedad de este hecho que no solamente perjudica seriamente a los países deudores, sino que a todos los países en desarrollo, al privárseles de recursos indispensables para elevar sus tasas de crecimiento.

Demás está decir que la crisis de los centros incide en forma muy grave sobre la periferia, acentuando las consecuencías de su propia crisis, consecuencias que no solamente son económicas sino sociales y políticas. Se exalta la significación del retorno a la democracia de nuestros países, pero acaso no se perciba qué riesgos y problemas implica esta crisis para la estabilidad política y social de los países latinoamericanos.

\section{VII}

\section{Post scriptum}

Terminado este artículo llegó a mi conocimiento que tres instituciones de gran prestigio han tomado la encomiable decisión de emprender la formulacion de una nueva estrategia de desarroloo para América Latina. Se trata del Colegio de México, la Fundación Getulio Vargas y el Institute for International Economics de Washington. He recibido copia de los dos primeros capítulos en donde se presentan los primeros resultados de un análisis en que se compara desfavorablemente el desarrollo de los países latinoamericanos con el de otros páses en desarrollo. No es mi propósito entrar en este análisis sino tan sólo referirme a una afirmación que allí se hace acerca de la responsabilidad de la CEPAL en la política de comercio exterior de los países latinoamericanos incluidos en el estudio tripartito. Se dice allí en efecto: "En los primeros años de postguerra se advirtió en América Latina un cambio de política: el énfasis no se colocó ya en las exportaciones sino en la sustitución de importaciones. Los fundamentos teóricos de este vuelco los había dado la Comisión Económica para América Latina de las Naciones Unidas, que veía escasas posibilidades de lograr un acele rado crecimiento económico mediante la expansión de las exportaciones. Se sostenía que, por el descenso secular de sus coeficientes de importación, los países industrializados desarrollados no darían un estímulo suficiente para el crecimiento económico sobre la 
base de las exportaciones de productos primarios; que los paises latinoamericanos no estaban en condiciones favorables para desarrollar la exportación de manufacturas; y que había una tendencia histórica al deterioro de la relación de precios del intercambio de estos países, es decir la relación entre los precios de exportación e importación"."

Es una afirmación completamente arbitraria por desconocer los trabajos de la cepal, como paso a demostrarlo, en la esperanza de que en una versión posterior del trabajo se rectifique el grave error que se comete.

Así, en un informe publicado en $1959^{3}$ se expresa:

"La sustitución de importaciones no es una operación sencilla y de horizontes ilimitados. Una política persistente de sustituciones que no vaya acompañada de aumentos en la productividad puede alcanzar un punto más allá del cual se llega a una reducción de las exportaciones, es decir, a una pérdida neta de divisas. En efecto, a menos que sea espontánea, la sustitución obliga a la adopción de medidas proteccionistas que se tienen que ir acentuando conforme se agotan aquellos campos de sustitución en que son menores las diferencias de productividad entre el pais y el resto del mundo. A consecuencia de esa creciente protección suben los costos internos y afectan la rentabilidad de las exportaciones, que es distinta para los diferentes productos que las componen. En una primera etapa de la sustitución puede ocurrir que la disminución de la rentabilidad de la exportación no sea suficiente para reducir su volumen, pero es perfectamente posible que si se sigue avanzando comiencen a desaparecer en grado creciente las exportaciones marginales y pueda alcanzarse un punto en que lo que se economiza por sustitución se pierda en exportaciones. Como es natural, mientras más amplios sean los márgenes de rentabilidad de las exportaciones y menor la necesidad de protección, puede irse más lejos con la sustitución sin alcanzar el punto crítico.

"El análisis ha permitido concluir que el lento crecimiento de la demanda de los productos tra-

\footnotetext{
${ }^{2}$ Traducido del original inglés.

"Vease CEPAL, El mercado común latinoamerizano, publicación de Naciones Unidas, $\mathrm{N}^{\circ}$ de venta: 59.11.G.4.
}

dicionales de exportación y el mantenimiento del ritmo de crecimiento del producto registrado ent el pasado exigen una sustitución tan acelerada de las importaciones que no parece ser una tarea factible aun cuando lleguen a darse condiciones muy favorables de financiamiento externo.

"Cuál es entonces el camino abierto a los países latinoamericanos para resolver el estrangulamiento que impone la escasez de divisas? Hay en realidad dos: uno serra el de una gran expansion de exportaciones distintas a las tradicionales hacia los paises situados fuera del area; otro, el de una expansión del comercio interlatínoamericano que se apoye en un proceso acelerado de sustitucion de importaciones provenientes de otras regiones, pero realizada en un ámbito regional y mediante un intercambio más activo de los productos tradicionales.

"El primero de estos caminos requerina un giro notable en la dirección que hasta ahora ha seguido la poltica comercial de los paises desarrollados, en el sentido de que los aranceles, y demas restricciones que suelen ponerse en practica, dieran hugar a que los países latinoamericanos pudieran aprovechar las ventajas comparativas que les ofrecen su dotación de recursos y su situación geografica. El segundo camino exige la transformación paulatina de las bases sobre las que se ha desarrollado hasta hoy el comercio interlatinoamericano, de tal manera que se aprovechen las ventajas que puede representar el amplio mercado de la región, pero al mismo tiempo sin sacrificar las posibilidades de desarrollo de los paises de más bajo nivel de ingreso.

"Estos dos caminos no son incompatibles entre sí y una utilización adecuada de ambos redundaría en beneficio tanto de América Latina como de los países más desarrollados del resto del mundo. Analizar el efecto que podría ejercer una transformación de la política comercial de los grandes centros industriales merece un detallado estudio. Aquí se examinan únicamente las posibilidades de resolver el estrangulamiento por medio de la organización de un mercado común.

"El establecimiento de un mercado común tiene la ventaja de que -sin perjudicar las posibilidades de especialización- permite llegar más lejos en el proceso de sustitución de lo que sería posible en el ámbito del mercado de cada país. América Latina considerada como un conjunto reduce su demanda de importaciones prove- 
nientes de fuera del área a un nivel que es compatible con su disponibilidad de divisas y, al mismo tiempo, cada uno de los países miembros del mercado puede mantener un coeficiente alto de importaciones, aunque trasladando en proporciones variables su origen a la propia región."

Poco tiempo después y en 1961, siendo yo Secretario Ejecutivo de la CEPal se publicó un estudio mío ticulado "Desarrollo económico, planeación y cooperación internacional" en donde, por primera vez, que yo sepa, se hizo una crítica severa de la política de industrialización, un cuarto de siglo antes del trabajo en cuestión sobre una nueva estrategia. Vale la pena reproducir algunos párrafos pertinentes: ${ }^{4}$

"Las fallas fundamentales de la industrialización. Si bien la cuantía de la producción industrial no es arbitraria, su composición sí lo ha sido en la experiencia latinoamericana. Desde este punto de vista, el proceso de industrialización adolece de tres fallas fundamentales que han debilitado su contribución al mejoramiento del nivel de vida, a saber: a) toda la actividad industrializadora se dirige hacia el mercado interno; b) la elección de industrias se ha hecho por razones circunstanciales, más que por consideraciones de economicidad, y c) la industrialización no ha corregido la vulnerabilidad exterior de los paises latinoamericanos.

"La excesiva orientación de la industria hacia el mercado interno es consecuencia de la política de desar rollo seguida en los países latinoamericanos y de la falta de estímulos internacionales para sus exportaciones industriales.

"La poltica de desarrollo ha sido discriminatoria en cuanto las exportaciones. En efecto, se ha subsidiado - mediante aranceles $u$ otras restricciones- la producción industrial para el consumo interno, pero no la que podría destinarse a la exportación. Se ha desenvielto así la producción de numerosos articulos industriales de costos muy stuperiores a los internacionales, cuando pudo habérselos obtenido, con diferencias de costos mucho menores, a cambio de exportaciones de otros artículos industriales que podrian haberse producido más ventajosamente. Lo mismo podría decirse de nuevas líneas de exportación primaria y aun de líneas tradicionales dentro de ciertos límites relativamente estrechos.

\footnotetext{
${ }^{4}$ Tomado de la recopilación preparada por A. Gurrieri, La obra de Prebisch en la CEPAL. México, D.F.: Fondo de Cultura Econónica, Segunda Parte, pp. 84 y 85.
}

Y en otro trabajo "El falso dilema entre desarrollo económico y estabilidad monetaria", también publicado en 1961, se desarrollaron análogos conceptos en la siguiente forma:

"La discriminación contra las exportaciones. Es claro que el desarrollo de nuevas exportaciones -además de las tradicionales - ayudará considerablemente al cumplimiento de ese proposito. Esto nos lleva a examinar la otra falla fundamental: la asimetría de la política de desarrollo. La necesidad de sustituir importaciones, y de proteger para ello las actividades sustitutivas, ha sido ineludible. Pero no se ha dado el mismo estímulo a las exportaciones. Se ha discriminado en favor de la sustitución industrial y en contra de las exportaciones, principalmente de las exportaciones industriales. La política ideal habria sido dar a las exportaciones un estímulo que restableciera la paridad de condiciones con las actividades sustitutivas, y ello no significa necesariamente equivalencia de estímulos.

"Conviene examinar este aspecto por la importancia que reviste. Consiste esencialmente en lo siguiente. La limitación de la demanda exterior de exportaciones primarias obliga a destinar parte del incremento de factores productivos a actividades sustitutivas. Como su productividad es inferior a la de los grandes centros es necesario darles un subsidio de cierta cuantía en forma de protección aduanera. Sin embargo, existirían posibilidades de desarrollar con un subsidio de cuantía inferior nuevas actividades de exportación industrial, con las cuales se podría obtener por el intercambio mayor cantidad de artículos industriales que la que se conseguiría con la producción sustitutiva.

"Al subsidiarse esta última producción, y no la destinada a muevas exportaciones (industriales o primarias), se han malogrado posibilidades de exportar que, de haberse aprovechado eficazmente, habrían disminuido la amplitud de la política sustitutiva o habrian permitido un mayor ritmo de crecimiento de la economía."

También se cita en la página 12 del estudio tripartito sobre estrategia a Santiago Macario, economista de la CEPAL, quien críticó severamente los abusos de la política proteccionista de los paises latinoamericanos y también la de los países desarrollados. Expresa el Sr. Macario:

\footnotetext{
s/bid., pp. 18 y 19.
} 
"Salvo contadas excepciones, no se puede afirmar que haya una política proteccionista en los países latinoamericanos, si por tal debe entenderse un conjunto de medidas deliberadas y sistemáticas para hacer posible y estimular el desarrollo de ciertas industrias seleccionadas racionalmente dentro de un cuadro general de objetivos perseguidos con una política dada de desarrollo económico. Lo que sí ha habido y hay es proteccionismo, pero como resultado -en gran parte indirecto- de medidas especiales que a menudo se tomaron, por lo menos inicialmente o en una primera etapa, con carácter de emergencia para resolver problemas de balance de pagos o bajo la presión de otros factores exógenos. Estas medidas temporales se convirtieron en la mayoría de los casos en permanentes y se hicieron más generales, dando lugar a un proteccionismo cuyas características eran la improvisación, la falta de autonomía (por responder más que nada a cambios de origen externo), los niveles sumamente elevados y la aplicación indiscriminada. El objetivo fundamental de tal proteccionismo ha sido la sustitución de importaciones a cualquier costo y sin considerar cuáles industrias conviene más desarrollar y en qué medida."

El estudio tripartito menciona también que "con subsidios adicionales y una escasa protección a las importaciones, las exportaciones del sector manufacturero recibieron, en general, incentivos similares a los de la sustitución de importaciones en los países del Lejano Oriente" (p. 19). O sea, que han seguido una política similar a la que la CEPAL había recomendado a comienzos de los años sesenta a los paises latinoamericanos.

A la luz de las citas de nuestros escritos y de otros que no cabria mencionar por su redundancia: ¿es posible acusar a la cEPAL en los términos que se presentan en el capitulo I del trabajo en elaboración?

La cepal, en su afán de colaborar con los gobiernos de la región, ha presentado muchas sugerencias y recomendaciones. Algunas se han seguido, otras no. Es la suerte de toda iniciativa de esta naturaleza ¿podría responsabilizarse a la CEPAl de que los países se apartaran de tales recomendaciones y sugerencias?

6Santiago Macario, "Proteccionismo e industrialización en América Latina", Boletín Económico de America Latina, vol. $\mathrm{IX}, \mathrm{N}^{\circ} \mathrm{l}$, marzo de 1964, Naciones Unidas. 